$\infty$

0

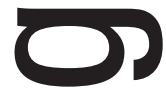

-

ת

1

$\longrightarrow$ 



\title{
O LOCAL E 0 REGIONAL: EXPERIÊNCIAS DE PLANEJAMENTO E A INTERVENÇÃO DOS ATORES
}

\author{
THE LOCAL AND REGIONAL: EXPERIENCES IN PLANNING AND OPERATION OF ACTORS
}

\author{
LOCAL Y REGIONAL: EXPERIENCIAS EN LA PLANIFICACIÓN Y \\ EL FUNCIONAMIENTO DE LOS ACTORES
}

\author{
Gisleide da Silva Couto - Universidade Federal de Goiás \\ gisleidegeografia@gmail.com
}

\begin{abstract}
Resumo
Este trabalho tem como objetivo discutir sobre o local e o regional como unidade de intervenção evidenciando as formas de articulação dessas escalas nas propostas de planejamento. Partindo do pressuposto de que os recortes, as escalas, as propostas de planejamento de qualquer natureza, estão diretamente vinculados aos interesses dos atores envolvidos, também apresentaremos uma discussão sobre a qualidade, as características e a capacidade real de transformação da realidade pelos diversos atores sociais, com destaque para o Estado. Conscientes das limitações dos planos nas diferentes escalas, no âmbito do modo de produção capitalista, cuja natureza, está embasada na desigualdade social, o artigo será finalizado com a apresentação de três experiências brasileiras de planejamento regional. Serão ressaltados sua metodologia, o recorte espacial e os resultados obtidos, sempre retomando a análise das articulações entre o local e o regional.
\end{abstract}

Palavras-chave: Local. Regional. Planejamento. Atores.

\begin{abstract}
This work has how I aim to talk about the place and the regional thing like unity of intervention showing up the forms of articulation of these scales in the proposals of projection. Proceeding from the assumption of what the cutting out, the scales, the proposals of projection of any nature, are straightly linked to the interests of the wrapped actors, also we will present a discussion on the quality, the characteristics and the real capacity of transformation of the reality for several social actors, with distinction for the State. Conscious of the limitations of the plans in the different scales, in the context of the way of capitalist production, which nature, it is embasada in the social unequality, the article will be finished by the presentation of three Brazilian experiences of regional projection. There will be emphasized his methodology, the space cutting out and the obtained results, always retaking the analysis of the articulations between the place and the regional thing.
\end{abstract}

Key-words: Location. Regional. Planning. Actors.

\section{Resumen}

Este documento tiene como objetivo discutir los entes locales y regionales como la unidad de intervención mostrando las formas de articulación de estas escalas en el proyecto de planificación. Suponiendo que los clips, las escalas, el planificación propuesto de cualquier naturaleza, están directamente vinculados a los intereses de los actores implicados, también presentan una discusión sobre la calidad, las características y la capacidad de transformar la situación real por los diversos actores sociales, destacando el Estado. Consciente de las limitaciones de los planes en diferentes escalas dentro del modo de producción capitalista, cuya naturaleza se basa en la desigualdad social, el artículo se finalizará con la presentación de tres experiencias brasileñas de la planificación regional. Su metodología se hizo hincapié, el corte del espacio y los resultados, siempre repitiendo el análisis de las articulaciones entre lo local y regional.

Palabras clave: Local. Regional. Planificación. Actores.

\begin{tabular}{|l|l|l|l|l|l|l|}
\hline Boletim Goiano de Geografia & Goiânia - Goiás - Brasil & v. 29 & n. 1 & p. 151-162 & jan. / jun. & 2009 \\
\hline
\end{tabular}




\section{Introdução}

Algumas experiências brasileiras de planejamento local e regional demonstram a necessidade de propostas que extrapolem a esfera municipal e, ao mesmo tempo, revelam as limitações de ações em escala regional desconectadas da esfera nacional, descaracterizando os objetivos destes tipos de planos. Este trabalho tem como objetivo discutir sobre o local e o regional como unidade de intervenção, evidenciando as formas de articulação dessas escalas nas propostas de planejamento. Partindo do pressuposto de que os recortes, as escalas, as propostas de planejamento de qualquer natureza, estão diretamente vinculados aos interesses dos atores envolvidos, também apresentaremos uma discussão sobre a qualidade, as características e a capacidade real de transformação da realidade pelos diversos atores sociais.

\section{0 local como unidade de intervenção}

Pensar o desenvolvimento local nos tempos atuais pode parecer simples, todavia, não há como fazê-lo sem considerar a questão regional. E por que isso? Primeiro por que não há como pensar os lugares, os locais isoladamente, como uma coleção de coisas desarticuladas entre si, existentes por si só, pois os lugares são resultantes de ações e processos sociais ao longo do tempo geograficamente localizados. Não há como pensar, assim, um lugar isoladamente, uma vez que os distintos atores sociais não estão enraizados no território como plantas ou rochas, ao contrário podem se deslocar pelo espaço e estabelecer articulações em distintas esferas de poder e escalas geográficas” (LIMONAD, 2004, p.49).

As questões trazidas pela autora são muito pertinentes ao tema, pois entender o território exige o domínio das simultaneidades escalares. Por isso, a escolha do local para o debate, destacando a sua impossibilidade de entendê-lo enquanto unidade isolada, evocando imediatamente a questão regional. E por que não é possível entender esse local isoladamente? Não é possível entendê-lo isoladamente na perspectiva dos atores e dos fluxos que têm o potencial de interação muito dinâmico.

Para complementar essa idéia de "local não isolado", é preciso tomar cuidado para não cair no erro que Bourdin (2001) chama de "vulgata localista". A vulgata gira em torno da aceitação do paradigma de que uma comunidade pode ser tratada como totalidade (abrangendo todos os aspectos da vida em sociedade), sem, contudo, submeter a afirmação ao rigor e aos métodos científicos para que seja difundida como "verdade”. De acordo com 
o autor, a "interrogação sobre as sociedades, em todas as suas dimensões (filosóficas, políticas etc.) enfoca objetos, que, num certo momento, parecem portadores de todas as grandes questões (p.27)”, no caso, o objeto local. São reducionismos que a ciência não deve incorrer se almeja compreender o fenômeno em sua essência, ou seja, é preciso ir além da manifestação direta e imediata do fenômeno através de um esforço sistemático e crítico, visando alcançar a realidade (KOSIK, 1976).

Nessa perspectiva do local como categoria importante para o planejamento e, ao mesmo tempo, considerando o risco de se cair numa vulgata localista, ressalta-se a indagação como bem questiona Haesbaert (1999, p.26) ao tratar da relação local/global: "O que, entretanto, estamos denominando de local?"

O autor enumera três perspectivas de análise do local. A primeira trata do local em oposição ao global. Nesse sentido, o global busca/conduz à homogeneização, e o local é resistência, a contracultura. Bourdin (2001) critica esta redução bipolar "mundo- microlocal", uma vez que, embora a mundialização coloque em discussão o território estável, bem delimitado, direcionando a uma forma de território em rede, constituído de pontos e fluxos, os lugares/local assumem importância de serem os pontos da rede. Não sendo a distância/proximidade o elemento principal da dinâmica, mas a co-presença ${ }^{1}$.

Esta definição aproxima-se da segunda perspectiva: a de local como ferramenta ${ }^{2}$, onde o local é tomado como instrumento de análise, escala geográfica de abordagem para tratar de fenômenos ligados ao cotidiano. O lugar e o local, neste sentido, são, ao mesmo tempo, as relações sociais espacializadas.

Por final, a perspectiva de local como sinônimo de lugar. Tanto Haesbaert (1999) como Bourdin (2001) bebem na fonte de Giddens (1991), admitindo que o local seja o cenário físico das relações sociais, portanto um lugar.

Alguns autores que discutem o local/regional, como Vainer (2007), Becker (2004) e Haesbaert (1999), ressaltam a globalização como fenômeno reestruturador da região. Esta reestruturação ocorre em função do caráter seletivo e pontual das ações globais que buscam vantagens locacionais (BECKER, 2004). Sobressaindo, portanto, em termos práticos, o local como unidade de intervenção. Na perspectiva de Haesbaert (1999, p.27) o global e o local formam um par dialético:

[...] na verdade o que temos é um continuum de diferentes níveis de hibridização entre condições locais, diferenciadas/diferenciadoras, e condições globais, 
mais universalizantes, desde os 'lugares-mundo', altamente conectados pelos fluxos globais, até os 'lugares-tribo', em tentativas de fechamento em torno de valores exclusivistas, espacialmente segregados.

Perceber esta hibridização em diferentes níveis significa admitir que as formas espaciais se articulam em redes ${ }^{3}$ a partir da interdependência entre o local e o global. Contudo, mais do que perceber a acepção dos conceitos, Boisier (1995) enfatiza a necessidade de uma análise que dê conta das interações, que detecte as ligações entre as diferentes esferas. Neste sentido, a discussão dos significados da escala regional poderá complementar o debate sobre a interdependência das diversas escalas e ser útil na tentativa de detectar as ligações e as formas de intervenção na realidade.

\section{0 regional como unidade de intervenção}

O recorte regional ou a escala regional tem como produto a região. De acordo com o contexto histórico e social, a categoria "região" sempre foi chamada para contribuir com a compreensão da realidade, ora com mais ênfase, ora como uma categoria complementar. Haesbaert (1999) destaca que a diversidade territorial serve como fundamento para a regionalização e traz para a discussão os elementos: desigualdade e diferença. Para o mesmo autor, o capitalismo global exacerba as desigualdades, tendo como base um valor-padrão. Benko e Lipietz (2000) tratam as desigualdades com o conceito de "regiões ganhadoras", indagando se as mesmas seriam regiões que se afirmam pela sua própria atividade ou regiões que vivem à custa das que perderam. No que se refere às diferenças, temos as singularidades, muitas vezes se configurando como movimento de resistência às tendências globais, não exigindo comparação a outras realidades (regiões).

A região também apresenta o complicador da busca pela síntese, tornando ainda mais complexa a análise regional com a sobreposição das escalas de ocorrência dos fenômenos sociais no mundo contemporâneo. Ainda assim existem autores que enfatizam o modo de produção capitalista como elemento por excelência de sua constituição. De acordo com Oliveira (1977, p.30):

O que preside o processo de constituição das 'regiões' é o modo de produção capitalista, e dentro dele, as 'regiões' são apenas espaços sócio-econômicos onde uma das formas do capital se sobrepõe às demais, homogeneizando a 'região' 
exatamente pela sua predominância e pela conseqüente constituição de classes sociais cuja hierarquia e poder são determinados pelo lugar e forma em que são personas do capital e de sua contradição básica.

Neste aspecto, a dimensão econômica se sobrepõe às demais, abrindo leque para a visão de região sob o ângulo da divisão territorial do trabalho, o que não é tão negativo, mas deve-se ter o cuidado de não cair numa visão reducionista do território.

Ao observar as propostas de planejamento regional, percebe-se a tendência de uma abordagem sistêmica com ênfase no econômico, pois, numa sociedade capitalista, as desigualdades sociais entre as classes costumam causar maior impacto sobre as tomadas de decisões. Surgindo, então, outro desafio que acompanha o conceito de região e o planejamento regional: Como a regionalização ocorre? Ou ainda, como regionalizar? Quais indicadores devem ser considerados?

Em Ribeiro (2004), a problemática é levantada através de dois elementos: regionalização como fato e regionalização como ferramenta. Os processos históricos da construção do espaço, as formas de estruturação e a dinâmica social sobre o território (território visto como campo de lutas e disputa de poder) configuram a regionalização como fato. O que possibilita a determinação de uma região, ou mesmo a identifica, é um conjunto de fatos historicizados independente do poder hegemônico do presente. É realmente uma construção histórica, que tanto pode provir de ações de manutenção do status quo, quanto de movimentos de resistência à homogeneização. No Brasil, um exemplo típico desta regionalização é o Nordeste. Uma identidade criada, presente nos mais variados discursos de defesa dos mais variados interesses.

Esta afirmação deixa a regionalização como fato atrelada à regionalização como ferramenta, muitas vezes utilizadas para forjar, por exemplo, um Nordeste com a expressão necessária para a conjuntura específica. A regionalização como ferramenta possui a mão forte do Estado como principal agente planejador responsável por destacar/selecionar os indicadores, institucionalizar e criar uma unidade analítica à determinada área (região).

Ambas as regionalizações, ressalta Ribeiro(2004), "envolvem ideologia e recursos político-administrativos", e mais do que a constatação da existência de uma região, está o poder de atores em produzi-las. 


\section{A intervenção dos atores}

[...] Como visto, no passado, e ainda no presente para certos setores, o Estado desempenha o papel central na viabilização financeira, industrial e política dos empreendimentos; isto significa que a legibilidade destes processos passa por um exame das formas prevalecentes de representação e disputa de interesses no interior mesmo do aparelho estatal” (VAINER, 2007, p.16).

É importante esta colocação de Vainer (2007) ao falar de planejamento territorial, destacando o Estado como ator central na realização de projetos desta natureza. Para tanto, levanta a questão do que é o Estado e da representação e interesses dominantes que compõem o próprio Estado.

Lojkine (1997) tece uma rica definição de Estado a partir da análise das classes sociais e do processo de (re)produção capitalista, rejeitando o conceito de Estado por uma relação de exterioridade com a estrutura social. Ao inverso, considera que o mesmo é um dos momentos da contradição fundamental entre a socialização do processo de trabalho e a apropriação privada dos meios de produção e do produto de trabalho. E quando o Estado não consegue regular de maneira minimamente estável as contradições do capitalismo ocorre uma crise. Esta crise gera propostas de mudanças de caráter reformista, e não, revolucionário. Esse é o motivo limitante do planejamento regional e das propostas de desenvolvimento local, pois, o principal agente, o Estado, trabalha em função da manutenção do capitalismo, cuja natureza, está embasada na desigualdade social.

A partir dessa lógica, o poder público no âmbito local assume a postura de competidor na tentativa de se tornar atraente aos investimentos. Markusen (2005, p.71), ao fazer uma análise econômica com enfoque nos atores, critica as estratégias de Estado (dos poderes maiores) que se desobrigam dos problemas da desigualdade espacial, atribuindo a tarefa às esferas de poderes menores:

[...] Sob a atraente idéia de "controle local”, a transferência de poderes é, na prática, uma nova e insidiosa prescrição adotada pelos governos nacionais e pelas organizações internacionais mais conservadoras, como o Banco Mundial e o FMI, para transferir responsabilidades de desigualdades espaciais para níveis de governo inferiores, especialmente países em desenvolvimento, sem recursos ou capacidade técnica para exercê-las [...].

De fato, colocar nas mãos do poder local o encargo de solucionar as disparidades espaciais é isentar-se da responsabilidade. O Estado seria, portanto, o principal agente de transformação se fosse capaz de favorecer as fra- 
ções de classes mais pobres em detrimento de ações que alimentem o grande capital e a concentração de renda. O que é um absurdo, pois, para isso ele teria de deixar de ser um Estado capitalista. A postura assumida pelos atores que compõem o Estado é de omissão do poder de transformação e de cumplicidade na reprodução do status quo. Suas ações deixam de ser as principais e passam a ser complementares.

No que se refere aos demais atores (sociedade civil organizada; instituições privadas; cada cidadão individualmente) Lojkine (1997) esclarece que é preciso precaução para "não confundir as suas representações e projeções com sua capacidade real de transformar as regras de funcionamento de nossa sociedade”, encerrando-se na problemática do ator, seja ele individual ou coletivo:

Intimamente persuadido de que nem tudo era um livre desempenho dos atores negociando seus interesses, mas desempenho muito mais complexo entre práticas e estruturas na espessura das temporalidades históricas, desempenho entre liberdade e necessidade, injunções ‘objetivas’ e dinâmica da produção do social [...] (p.11).

As influências das estruturas sobre os atores são muito mais acentuadas na escala local, onde a coerção é maior, as relações sociais/individuais são mais próximas, embora menos consciente. Contudo, as propostas de planejamento atuais tendem a mobilizar os atores locais para uma ação coletiva, o que pode ser tarefa difícil, pois as diferentes figuras da localidade, sua individualização, divergência de interesses, ilustram a complexidade entre as práticas e estruturas.

Existe algo mais que o desempenho dos atores, mas não quer dizer que exista uma vontade onipotente. A perspicácia dos atores (líderes) pode direcionar ou "determinar" o rumo de uma dada localidade. Daí a afirmativa de Gorender em Marx e Engels (1998, p. XVIII): "O que conta não é tão-somente identificar a procedência dos ladrilhos, mas ressaltar o autor do plano do edifício”.

Para perceber a importância da atuação dos atores e as relações interescalares, serão apresentadas a seguir algumas experiências recentes de planejamento regional realizadas no Brasil.

\section{Experiências de planejamento regional}

Algumas considerações serão feitas a respeito do plano de desenvolvimento da região do Seridó, no Rio Grande do Norte (ARAÚJO, 2005), do Estado do Paraná (ARAÚJO, 2000), e do Rio Grande do Sul (BROSE, 2005). 
O Seridó está inserido na região Nordeste, na parte atingida pelas secas. É complicado afirmá-lo uma região, quando, no caso Brasileiro, o Nordeste representa a questão regional. Neste sentido, o Seridó é uma sub-região nordestina composta por vinte e oito municípios. Segundo descrição de Araújo (2005), a identidade do Seridó está marcada principalmente por seus aspectos naturais, extrapolando os limites políticos/administrativo, além do aspecto da fé católica, e sua projeção na política estadual. Visto a partir das unidades territoriais que o compõem, pode-se afirmar que esta região nada mais é que a soma de localidades.

No caso da experiência de planejamento regional do Estado do Paraná, também apresentada por Araújo (2000), nota-se que por opção da política de Estado houve uma regionalização do território através de critérios proporcionadores de unidade da região como ferramenta ${ }^{4}$. No caso específico, foram escolhidas duas regiões definidas pelas respectivas associações municipais (AMUSEP e AMOP). Nota-se que a escala municipal é uma unidade de referência para constituição da região. Não é pretensão desta análise negar o planejamento regional e destacar as localidades representadas pelo município. O objetivo é detectar um projeto maior que não anule os municípios, mas que construa uma luta coletiva. Mesmo porque o Paraná já possui uma prática de planejamento urbano o que faz do plano regional deste Estado um "instrumento político de negociação” para os municípios, com destaque para ações de caráter regional (ARAÚJO, 2000). É um movimento de ida e volta do local ao regional.

O caso do Rio Grande do Sul, e último caso, também apresenta uma vasta experiência em planejamento regional e urbano, inclusive envolvendo a sociedade em geral de modo participativo. Ainda assim, existem grandes desigualdades no território gaúcho, originárias de um processo histórico de ocupação, como bem explanou Brose (2005), mas também de ações que perpetuaram uma conjuntura favorável à concentração de renda. Nota-se uma forte tendência às regionalizações, agregando municípios num projeto mais ou menos convergente de interesses entre os atores, por exemplo, com a criação dos conselhos regionais de desenvolvimento (COREDES). Em 1991, chegou-se a existir vinte e dois conselhos, reforçando a tendência das localidades em realizar operações consorciadas, com a finalidade de dinamizar os fluxos econômicos locais.

No Paraná, realizou-se descrição das regiões (AMUSEP e AMOP) enumerando-se algumas características consideradas importantes para o objetivo proposto, como: população por estado domiciliar; número de municípios; área territorial; cidades pólos; dados estatísticos econômicos (o PIB expres- 
sou a tendência agrícola para a região da AMOP e industrial para a região da AMUSEP); índice de urbanização, além de outros indicadores. Esta descrição constituiu a etapa do diagnóstico. As etapas seguintes foram: a do futuro desejável e ações prioritárias; e a escolha do modelo de gestão. Foi feita uma montagem de cenários extrapolando as escalas local e regional considerando a economia mundial, o Mercosul, a nacional e todo o Estado, fruto da visão dos atores no que se refere às limitações da estrutura econômica vigente.

Já as iniciativas de planejamento do Estado do Rio Grande do Sul se pautaram na lógica capitalista de competição, na tentativa de acompanhar o padrão de crescimento imposto mundialmente sob pena de ficarem às margens do sistema. O resultado dessas iniciativas são indicadores de desenvolvimento maiores que de outras áreas do país, porém, os benefícios conquistados não estão distribuídos de forma homogênea.

Na síntese das escolhas embutidas no plano de desenvolvimento sustentável ${ }^{5}$ do Seridó, prevaleceram os problemas estruturais do capitalismo de um modo geral, como: melhor distribuição de renda; acesso da população aos serviços sociais básicos; fortalecimento da democracia e ênfase no aspecto ambiental (que é comum a toda região).

O Paraná, ao adotar a concepção de desenvolvimento sustentável, assinalou o médio e longo prazo para se obter resultados, enfocando, principalmente, o enfrentamento e a redefinição da "base estrutural de organização da economia, da sociedade e das suas relações com o meio ambiente (ARAÚJO, 2000, p.71).” Contudo, não foi apresentada nenhuma proposta radical, ao contrário, prevaleceram propostas de tendências a minimizar a contradição capitalista permitindo sua manutenção (papel imprescindível do Estado). Os atores políticos foram tratados como peças-chave do planejamento regional, constatado através dos relatos das lições das experiências, nos quais ficou evidenciada a preocupação com o pouco envolvimento dos prefeitos no processo de elaboração do plano.

Para o caso do Rio Grande do Sul, especificou-se o plano de ação para a sua metade sul, no ano de 2003, com propostas viáveis de geração de empregos bem remunerados e de boa qualidade, com a finalidade de ampliação do mercado de consumo, possibilitando cidades saudáveis e serviços públicos de qualidade, atraindo mais empreendimentos econômicos, gerando riquezas locais e melhores salários. A lógica adotada foi simples: mais empregos significam maior capacidade de consumo; maior capacidade de consumo significa atração de empreendimentos para o município; e mais empreendimentos no município significam aumento da geração de riquezas 
locais. Um típico idealismo do capitalismo, como se tudo funcionasse em perfeita harmonia e complementaridade.

\section{Considerações finais}

A prática de planejamento regional e desenvolvimento local devem vir acompanhados de análise conceitual, definindo claramente as fundamentações e tendências que influenciarão nas tomadas de decisões. Este esclarecimento deve ser feito com maior ênfase e cautela, principalmente aos atores sociais chamados a participarem de um processo tão importante e complexo (planejar uma coletividade).

As discussões aqui apresentadas objetivaram contribuir com esta tarefa conceitual: perceber o local/lugar em suas múltiplas facetas. Como o global está presente no lugar? Até que medida a região e a regionalização tornam a organização espacial inteligível? Como os atores têm se inserido nas ações de intervenção da realidade e como as simultaneidades escalares estão sendo tratadas nestas propostas de ações?

Analisou-se, também, o Estado como um ator em potencial para propor e realizar mudanças, capaz de atuar significativamente pela melhoria das condições de vida e maior justiça social. Contudo, contenta-se em ser um ator característico do capitalismo, cumpridor de sua função como regulador das contradições do sistema, representado por interesses específicos, mas representante da sociedade em geral.

Assim, as experiências de planejamento, no caso brasileiro, no interior do modo de produção capitalista, apresentam insuficiências na busca por maior distribuição de renda, diminuição das desigualdades sociais/territoriais, geração de emprego. Isto não significa descartar as tentativas feitas, muito menos desacreditar nas tentativas futuras. Quaisquer que sejam os atores movidos por uma causa coletiva, eles devem conhecer a realidade posta, o contexto regional que a dada localidade esteja inserida, e ao mesmo tempo ter consciência das limitações de qualquer intervenção proposta, se não atacar a raiz do problema.

1 Bourdin (2001, p. 62) exemplifica a co-presença através de seus efeitos: “[...] Entre eles, alinharemos tanto a reunião de consumidores dos mesmos serviços, que permite a presença desses serviços, quanto os efeitos de dinâmica social [...] causados pela reunião ligada à celebração de uma liturgia ou a um evento, ou ainda pela simples reunião fortuita de diversos objetos, o amontoado urbano, por exemplo, que produz efeitos de diversidade, causadores de outros efeitos [...]". 
2 Empréstimo feito de Ribeiro (2004).

3 Não se deve pensar a rede de uma maneira estática, e mesmo suas linhas (fluxos) não precisam, necessariamente, de concretude para cumprirem sua função de conexão entre os pontos. Na medida em que a tecnologia avança, tornam-se mais fluidas e rápidas as conexões entre os lugares, permitindo uma acentuada divisão do trabalho, onde a produção, distribuição e consumo podem estar em quaisquer partes do mundo integrados em uma única rede.

4 Obviamente que estes critérios não são aleatórios, o que justifica uma regionalização como fato (conceitos já discutidos neste texto).

5 A concepção de desenvolvimento sustentável foi adotada para direcionar as propostas do plano, embora todas as experiências que aqui serão relatadas optaram por este conceito. Afinal, quem não concorda com o desenvolvimento sustentável?

\section{Referências}

ARAUJO, Tânia Bacelar de. A experiência recente de planejamento regional do Estado do Paraná - os casos das regiões do Oeste do Setentrional Paranaense. In: Ensaios sobre o desenvolvimento brasileiro - heranças e urgência. Rio de Janeiro: REVAN, FASE, 2000.

ARAUJO, Tânia Bacelar de. Rio Grande do Norte - a contribuição da experiência do Seridó. In: CRUZ, J. Luiz Viana da (Org.). Brasil, o desafio da diversidade - experiências de desenvolvimento regional. Rio de Janeiro: SENAC, 2005.

BECKER, Bertha. Uma nova regionalização para pensar o Brasil. In: LIMONAD, E., HAESBAERT, R., MOREIRA, R. (Org.). Brasil século XXI - por uma nova regionalização? Agentes, processos e escalas. Rio de Janeiro, Marx Limonad, 2004.

BENKO, G. \& LIPIETZ, A. O novo debate regional. In.: Regióes ganhadoras, distritos e redes. Portugal: Oeiras, 2000.

BOISIER, Sergio. Post-scriptum sobre desenvolvimento regional: modelos reais e modelos mentais. Chile: Planejamento e Políticas Públicas, nº 13, 1995.

BOURDIN, Alain. A questão local. Rio de Janeiro: DP\&A, 2001.

BROSE, Markus Erwin. Rio Grande do Sul: superação das desigualdades regionais - uma interpretação da experiência gaúcha. In: CRUZ, J. Luiz Viana da (Org.). Brasil, o desafio da diversidade - experiências de desenvolvimento regional. Rio de Janeiro: SENAC, 2005.

GIDDENES, A. As conseqüências da modernidade. São Paulo: EdUNESP, 1991.

HAESBAERT, Rogério. Região, diversidade territorial e globalização. In: GEOGRAPHIA, ano $1, \mathrm{n}^{\circ} 1,1999$.

HAESBAERT, Rogério. RS: latifúndio e identidade regional. Porto Alegre: Mercado Aberto, 1988.

KOSIK, Karel. Dialética do Concreto. Tradução de Célia Neves e Alderico Toríbio, $2^{\mathrm{a}}$ ed. Rio de Janeiro, Paz e Terra, 1976.

LIMONAD, Ester. Desarrollo local, la cuestión regional, las nuevas tecnologias, algunos puntos para reflexión. V Colóquio sobre Transformaciones Territoriales. Nuevas Visones En El Inicio Del Siglo XXI. Argentina: Universidad de la Plata, 2004. 
LOJKINE, Jean. O Estado capitalista e a questão urbana. $2^{\mathrm{a}}$ ed. São Paulo: Martins Fontes, 1997.

MARKUSEM, Ann. Mudança econômica regional segundo o enfoque centrado no ator. In.: DINIZ, Clério Campolina \& LEMOS, Mauro Borges (Org.). Economia e território. Belo Horizonte: Editora da UFMG, 2005.

MARX, Karl \& ENGELS, Friedrich. A ideologia alemã. [Introdução de Jacob Gorender]: tradução Luis Claudio de Castro e Costa - São Paulo: Martins Fontes, 1998.

OLIVEIRA, Francisco de. Elegia para uma re(li)gião. $2^{\text {a }}$ ed. Rio de Janeiro: Paz e Terra, 1977.

RIBEIRO, Ana Clara Torres. Regionalização: fato e ferramenta. In: LIMONAD, E., HAESBAERT, R., MOREIRA, R. (Org.). Brasil século XXI - por uma nova regionalização? Agentes, processos e escalas. Rio de Janeiro, Marx Limonad, 2004.

VAINER, Carlos. Fragmentação e projeto nacional: desafios para o planejamento regional. In: XII ENA (Encontro Nacional da ANPUR). Belém: 2007.

Gisleide da Silva Couto - Mestre em geografia pelo Instituto de Estudo Sócio Ambientais - UFG.

Recebido para publicação em Dezembro de 2008

Aceito para publicação em Março de 2009 